\title{
ASSESSMENT OF MULTI-GNSS PRECISE ORBIT AND CLOCK PRODUCTS FROM DIFFERENT ANALYSIS CENTERS BASED ON PRECISE POINT POSITIONING
}

\author{
Weiguo LI and Michal KAČMǍ̌íK **
}

Department of Geoinformatics, V̌̌B-Technical University of Ostrava, 70800 Ostrava, Czech Republic

*Corresponding author's e-mail: michal.kacmarik@vsb.cz

\begin{tabular}{|c|c|}
\hline ARTICLE INFO & ABSTRACT \\
\hline Article history: & \multirow{10}{*}{$\begin{array}{l}\text { Performance of } 24 \mathrm{~h} \text { static Precise Point Positioning (PPP) solutions based on multi-GNSS precise } \\
\text { satellite orbit and clock products from four analysis centers and seven various constellation } \\
\text { combinations was studied to evaluate their quality and characteristics. Data from ten European and } \\
\text { four Chinese GNSS stations and } 152 \text { days long period from year } 2020 \text { were processed. Obtained } \\
\text { coordinates were firstly compared with those provided by IGS final weekly combined solution. In } \\
\text { Europe, the best agreement with this reference product was reached by solutions including Galileo } \\
\text { signals, namely by a combination of GPS+GLONASS+Galileo systems with a mean RMS of } \\
11 \mathrm{~mm} \text {. This situation was different in China where inclusion of Galileo always led to worse results } \\
\text { and the best agreement was achieved by a combination of GPS+GLONASS systems. Although } \\
\text { product provided by German Research Center for Geosciences (GFZ) could be selected as the best } \\
\text { performing over Europe and product by Center for Orbit Determination in Europe (CODE) over } \\
\text { China, differences between individual precise products were mostly at a minimal level. Secondly, } \\
\text { coordinates repeatability over the processed period was computed in order to assess the positioning } \\
\text { stability. In this regard, the lowest values in both horizontal and vertical direction were reached by } \\
\text { GPS+GLONASS solutions. From the perspective of precise products, the repeatability results } \\
\text { were dependent on the selected constellation where mainly a specific behavior of product from } \\
\text { Wuhan University (WUM) for Galileo system was observed. }\end{array}$} \\
\hline Received 21 May 2021 & \\
\hline Accepted 16 July 2021 & \\
\hline Available online 22 July 2021 & \\
\hline Keywords: & \\
\hline Multi-GNSS & \\
\hline Precise products & \\
\hline & \\
\hline & \\
\hline & \\
\hline
\end{tabular}

\section{INTRODUCTION}

Development of new Global Navigation Satellite Systems (GNSS) as Galileo or BeiDou Navigation Satellite System (BDS) as well as a modernization of legacy systems GPS and GLONASS is linked with a transition from single or dual constellation solutions to multi-GNSS combined solutions. Increase in a number of available satellites and their signals offered by triple or quad constellations was already proved to lead into better quality of positioning realized in various modes (see i.e. Li et al., 2015; Guo et al., 2017a; Zhao et al., 2020) or tropospheric parameters (Douša et al., 2018). Better quality of positioning is not only related to its absolute accuracy, but also to its availability and robustness in areas with a limited view over the sky, shorter periods of observation needed to reach a desired accuracy or an ability of cheaper single-frequency multi systems receivers to be competitive with dual-frequency single system ones (Odolinski and Teunissen, 2017).

All new processing strategies and models developed for multi-GNSS positioning can be beneficial if only high-quality precise orbit and clock products (below referred as precise products) for all mentioned GNSS are available for the user. This requirement is critical mainly for the Precise Point
Positioning (PPP) technique (Zumberge et al., 1997) which uses un-differenced observations from a single receiver rather than for positioning techniques based on forming single- or double-differenced observations and therefore allowing a direct cancellation of some of the observation errors. PPP technique can provide sub-centimeter level of accuracy in static post-processing mode (Gandolfi et al., 2017) and few centimeters level of accuracy in real-time kinematic mode (Li et al., 2015). Length of observation session plays an important role in this regard when better results in shorter sessions can be achieved by utilizing signals from more GNSS systems (Pan et al., 2019) or if applying the ambiguity resolution (Geng et al., 2010).

In 2011, International GNSS Service (IGS, http://www.igs.org/; Johnston et al., 2017) established the Multi-GNSS Experiment (MGEX) project in order to stimulate and coordinate a transition to a multiGNSS era. Despite significant achievements of the MGEX project summarized i.e. in Montenbruck et al. (2014) and Montenbruck et al. (2017) including also a routine provision of precise multi-GNSS products by several analysis centers (AC), there is still no official combined multi-GNSS precise product available. Since individual ACs apply different processing 
strategies and models in their multi-GNSS orbit and clock products determination, differences in their characteristics and quality are expectable.

Various evaluations of multi-GNSS real-time and post-processing precise products quality were published in recent years. Their authors focused either on an evaluation of the satellite orbits and clocks themselves (Montenbruck et al., 2017; Guo et al., 2016; Guo et al., 2017b; Kazmierski et al., 2018; Wang et al., 2018; Li et al., 2020; Steigenberger and Montenbruck, 2020) or on quantifying their impact on positioning in terms of coordinates accuracy, precision and optionally also on a convergence time of PPP solutions. First studies evaluating quality of GNSS PPP positioning based on quad constellations were presented by Tegedor et al. (2014) and Cai et al. (2015). Although only a limited number of Galileo and BDS satellites were available in these days, both studies already showed some benefits of multi-GNSS combinations over single system PPP solutions. Li et al. (2017) examined thoroughly a performance of single-frequency PPP solutions and found a significant improvement in positioning for a quad system solution over the single system ones. Kiliszek et al. (2018) and Mohammed et al. (2018) realized studies assessing impact of various precise products provided by IGS or individual MGEX ACs on static PPP positioning accuracy and convergence time, however they both used only GPS and GLONASS signals.

Work of Bahadur and Nohutcu (2019) provided a detailed assessment of precise products availability and PPP positioning accuracy and convergence time behavior based on precise products from six MGEX ACs and ten IGS GNSS stations, one month of data from May 2018 and twelve combinations of GPS, GLONASS, Galileo and BDS systems. During the processed period, PPP solutions utilizing precise products from German Research Center for Geosciences (GFZ) and Wuhan University (WUM) achieved in overall a relatively better positioning performance compared to solutions utilizing other precise products. In combined multi-GNSS solutions, the GPS system was found to be still dominating the quality of positioning. Zhou et al. (2020) used 90 MGEX GNSS stations and one month of data from April 2019 to evaluate PPP performance of GPS-, GLONASS- and Galileo-only solutions based on precise products from eight IGS and five MGEX analysis centers. Positioning accuracy and convergence times were studied in static and kinematic mode. While positioning performance of GPS- and GLONASS-only solutions was found to be similar with many of tested precise products, for Galileo-only solution the GRM product from Centre National d'Etudes Spatiales (CNES) worked the best. And in overall, precise products provided by Center for Orbit Determination in Europe (CODE) reached the highest rank. Except assessing precise orbits and clocks themselves, Li et al. (2020) used also results of PPP static and kinematic positioning to evaluate performance of GPS-, Galileo- and BDS-only solutions utilizing different MGEX products. Data from a single day October 21, 2019 collected at six GNSS stations situated in Asia and Australia were processed. While in static mode Galileo-only solutions reached similar horizontal accuracy as GPS-only solutions with all the tested precise products, in case of BDS-only solutions the same situation was achieved only with precise products from WUM. Provided reason of this situation was that only the WUM product contained all operational BDS-2 and BDS-3 satellites. Recently, Li and Kačmařík (2021) analyzed three various multi-GNSS precise orbit and clock products provided by the Wuhan university using data from eight GNSS stations over five months long period in 2020. The performance of the rapid version of the product was found to be close to the final one while the predicted part of the ultra-rapid product led to significantly worse results. In this regard, a positive effect on positioning accuracy was reached when including Galileo signals in processing of the predicted part of the ultra-rapid product.

Within this work positioning performance of PPP multi-frequency solutions run in $24 \mathrm{~h}$ post-processing static mode is assessed while utilizing precise products from four MGEX analysis centers and signals from single to quad constellations. Compared to all studies mentioned in the previous paragraph except the one by Li and Kačmarrík (2021), it is based on data from a much longer time period to ensure robust results with a limited influence of potential short-term variations in quality of precise products and/or observation data from GNSS stations. Set of ten European and four Chinese GNSS stations is evaluated separately to show potential differences between these two regions. The last comprehensive study evaluating quality of multi-GNSS precise orbit and clock products using PPP processing results published by Bahadur and Nohutcu (2019) was based on data from May 2018 when there were only 15 active Galileo satellites and 14 active BDS satellites. During the period processed in this work (January till May, 2020), constellations of both new systems were more developed as there were 22 operational Galileo satellites and the BDS-3 reached its full constellation on June 23, 2020. Moreover, according to Steigenberger and Montenbruck (2020) the quality of multi-GNSS precise products is mainly for new systems improving in time. The purpose of this study is therefore to provide current information on which precise product(s) and what combination(s) of GNSS constellations can within Europe and China provide the most accurate positioning.

\section{MATERIALS AND METHODS}

\subsection{DATASET}

As part of the MGEX project, eight ACs provide their own precise products in a form of satellite orbits (SP3 format), corrections of satellite clocks (CLK format) and Earth rotation parameters (ERP format) 
Table 1 Overview of the MGEX ACs (http://mgex.igs.org/IGS MGEX Products.php) and ESA/ESOC (http://navigation-office.esa.int/GNSS based products.html) precise products used in this study. Used abbreviations: G (GPS), R (GLONASS), E (Galileo), C (BDS), J (QZSS).

\begin{tabular}{llll}
\hline Institution & Prefix & Constellations & \multicolumn{1}{c}{ Products (Sample interval) } \\
\hline CODE & COD & G+R+E+C+J & SP3 (5min), CLK (30s/5min), ERP (12h) \\
ESA/ESOC & ESA & G+R+E+C+J & SP3 (5min), CLK (30s), ERP (24h) \\
GFZ & GFZ & G+R+E+C+J & SP3 (5min), CLK (30s/5min), ERP (24h) \\
Wuhan University & WUM & G+R+E+C+J & SP3 (15min), CLK (5min), ERP (24h) \\
\hline
\end{tabular}

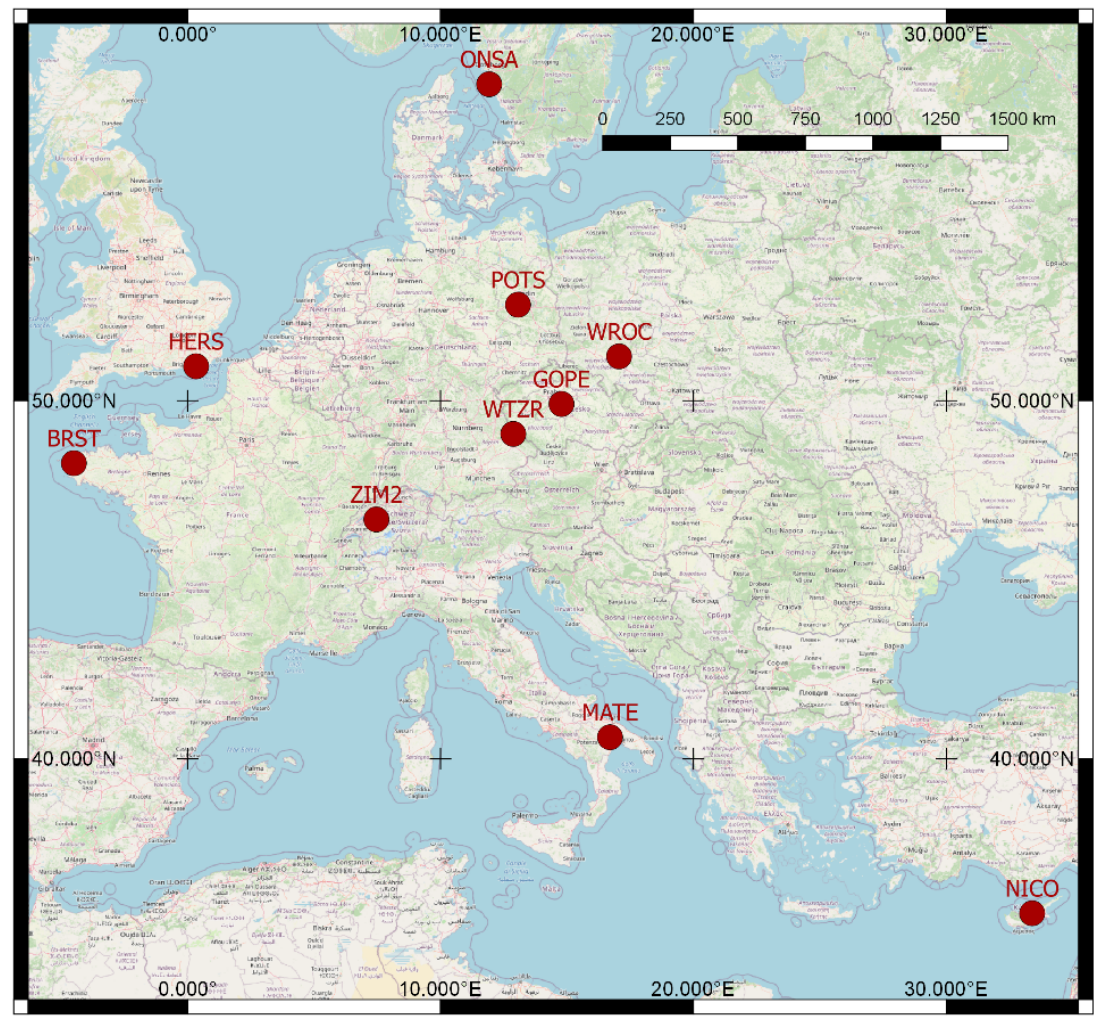

Fig. 1 Location of the ten European MGEX GNSS stations used in the study.

based on their own processing strategy and MGEX network of multi-GNSS stations. Three of the ACs currently do not provide products for all four systems, they abbreviations are: CNES/CLS, JAXA and TUM. Within this study, multi-GNSS products from CODE (Prange et al., 2020), GFZ (https://www.gfzpotsdam.de/en/section/space-geodetic-

techniques/projects/mgex/) and WUM MGEX analysis centers were evaluated together with the multi-GNSS final precise product provided by European Space Operations Centre (ESOC) within the European Space Agency (ESA). Although the ESA/ESOC analysis center is not a part of the MGEX project, its multiGNSS final precise product can represent a good alternative. Basic characteristics of all precise products evaluated in this study are listed in Table 1 . It should be noted that for the BDS system, COD and GFZ products during the time period processed in this study contained only BDS-2 satellites while ESA and
WUM products contained both BDS-2 and BDS-3 satellites.

Data collected at fourteen GNSS stations over 152 consecutive days from January till May 2020 were used in this study. All ten GNSS stations located in Europe and four stations located in China are part of the global IGS MGEX network and equipped with multi-GNSS hardware. Position of European stations is presented in Figure 1 and their basic characteristics are provided in Table 2.

\subsection{DATA PROCESSING}

RTKLIB open source program package (Takasu, 2009, http://www.rtklib.com/) in version 2.4.3 b34 was used for PPP processing within this study. The software offers various GNSS positioning techniques based on un-differenced or double-differenced observations and can be run in static or kinematic mode, in real-time or in post-processing. Signals from 
Table 2 Basic information about ten European and four Chinese GNSS MGEX stations used in the study.

\begin{tabular}{lllllr}
\hline Station & Country & Receiver & Antenna & \multicolumn{2}{c}{ Location $\left(^{\circ}\right)$} \\
\cline { 4 - 5 } & & & & Latitude & Longitude \\
\hline BRST & France & TRIMBLE ALLOY & TRM57971.00 NONE & 48.3805 & -4.4966 \\
GOPE & Czech Republic & TRIMBLE ALLOY & TPSCR.G3 TPSH & 49.9137 & 14.7856 \\
HERS & United Kingdom & SEPT POLARX5TR & LEIAR25.R3 NONE & 50.8673 & 0.3362 \\
MATE & Italy & LEICA GR30 & LEIAR20 NONE & 40.6491 & 16.7045 \\
NICO & Cyprus & LEICA GR50 & LEIAR25.R4 LEIT & 35.141 & 33.3964 \\
ONSA & Sweden & SEPT POLARX5TR & AOAD/M_B OSOD & 57.3953 & 11.9255 \\
POTS & Germany & JAVAD TRE_3 & JAVRINGANT_G5T & 52.3793 & 13.0661 \\
& & & NONE & & 17.062 \\
WROC & Poland & LEICA GR50 & LEIAR25.R4 LEIT & 51.1133 & 12.8789 \\
WTZR & Germany & LEICA GR50 & LEIAR25.R3 LEIT & 49.1442 & 7.465 \\
ZIM2 & Switzerland & TRIMBLE NETR9 & TRM59800.00 NONE & 46.8771 & 114.335 \\
HKWS & China & LEICA GR50 & LEIAR25.R4 LEIT & 22.434 & 114.491 \\
JFNG & China & TRIMBLE NETR9 & TRM59800.00 NONE & 30.516 & 87.601 \\
URUM & China & JAVAD TRE_3 & JAVRINGANT_G5T & 43.808 & 114.357 \\
& & & NONE & & \\
WUH2 & China & JAVAD TRE_3 & JAVRINGANT_G5T & 30.532 & \\
& & & NONE & & \\
\hline
\end{tabular}

Table 3 Information on PPP processing applied in the study.

\begin{tabular}{cc}
\hline Processing mode & PPP-static in 24h window \\
\hline Strategy & forward extended Kalman filter \\
Observation sampling rate & $30 \mathrm{~s}$ \\
Precise products & multi-GNSS final precise products from various ACs \\
Frequency & L1, L2 and L5 \\
Ionosphere & ionosphere-free linear combination \\
Troposphere & a priori Zenith hydrostatic Delay (ZHD) Saastamoinen model (Saastamoinen, \\
& 1973), Zenith Total Delay (ZTD) corrections and tropospheric gradients \\
& estimated epoch-wise \\
Mapping function & Niell (Niell, 1996) \\
Cut-off elevation angle & $5^{\circ}$ \\
Observation weighting & $1 / \sin ^{2}(e l e v a t i o n)$ \\
Antenna model & igs 14_2062.atx \\
Ocean tidal loading & applied (FES2004) \\
Differential code biases & CODE DCB monthly product \\
(DCB) files & \\
\hline
\end{tabular}

GPS, GLONASS, Galileo, BDS and QZSS systems are supported.

PPP in RTKLIB is available in three different versions - PPP kinematic (receiver is moving during the measurement), PPP static (receiver position is static during the measurement) and PPP fixed (coordinates of the receiver are fixed to a known position and only other unknown parameters are estimated from observations). In this study the second option was used. An extended Kalman filter is implemented for unknown parameters estimation during the PPP processing. In this study, standard 24h observation RINEX3 files with 30 s sampling were processed with settings given in Table 3 . RTKLIB is applying down-weighting of GLONASS observations by a factor of 1.5 to reflect both a lower quality of precise products and observations. GPS, Galileo and
BDS systems use the same weighting of 1.0. These settings cannot be changed without a modification of RTKLIB source codes.

\subsection{METHODOLOGY OF THE EVALUATION}

We realized our study in a two-step approach to effectively analyze quality of PPP processing with individual multi-GNSS products and various combinations of GNSS constellations. In the processing stage, data from all GNSS stations and all four ACs were processed over the full period using seven various constellation configurations: G, GR, GE, GC, GRE, GRC, GREC.

In the first step of evaluation stage, obtained daily coordinates were compared with those from the official IGS final weekly solution (IGS, 2021). The IGS solution represents a robust positioning product 
computed as a combination of GPS+GLONASS solutions delivered by individual IGS analysis centers. Values of 3D distance between daily coordinates from own processing and the IGS solution were computed and are referred as 3D distance error in presented statistical evaluations. Differences in individual coordinate components (North, East, Up) between daily coordinates from own processing and the IGS solution were computed and used for the evaluation as well.

No removal of outlying values was applied as differences between daily $X, Y, Z$ coordinates from own PPP processing and the IGS final weekly solution stayed mostly below $\pm 15 \mathrm{~mm}$ and rarely exceeded $\pm 35 \mathrm{~mm}$.

Later, an evaluation of repeatability of coordinates was realized for all seven constellation configurations and all ACs products. Repeatability of coordinates during the processed period was computed for all three coordinate components (North, East, Up) as a standard deviation (STD) of their daily values. Besides that, repeatability in 2D horizontal direction was obtained using the formula:

$2 D$ horizontal repeatability $=\sqrt[2]{S T D_{N}^{2}+S T D_{E}^{2}}$

where $S T D_{N}\left(S T D_{E}\right)$ corresponds to the repeatability of the North (East) component respectively. Daily coordinates were not aligned to a unified reference epoch before the repeatability computation.

\section{RESULTS}

\subsection{STEP 1: COMPARISON OF OWN PPP RESULTS} WITH IGS FINAL WEEKLY SOLUTION

As abovementioned, in order to assess performance of PPP post-processing positioning based on various multi-GNSS precise products we firstly compared coordinates of RTKLIB solutions with IGS weekly combined solution. Figure 2 shows 3D distance errors between coordinates obtained from own PPP processing using GRE constellation configuration and the IGS weekly combined solution for processed GNSS stations and all four analyzed multi-GNSS precise products. From the perspective of analyzed GNSS stations, mean values ranged between 7 and $11 \mathrm{~mm}$ with an exception for BRST (URUM) stations reaching up to 15 (20) $\mathrm{mm}$ respectively. Differences among individual precise products were mostly hardly noticeable.

In following parts of the document results based on a set of processed European and Chinese stations are presented separately. It is important to note that since only a limited number of stations was processed, absolute values of statistical parameters for China and Europe should be compared directly to each other only with a caution.

Mean differences between own PPP processing and IGS weekly combined solution in individual coordinate components (North, East, Up) are shown in Figure 3 for European stations and in Figure 4 for Chinese stations. Combining GLONASS or BDS system with the GPS had mostly minimal impact at the level of 1-2 mm with respect to the GPS-only results in any coordinate component. When including Galileo
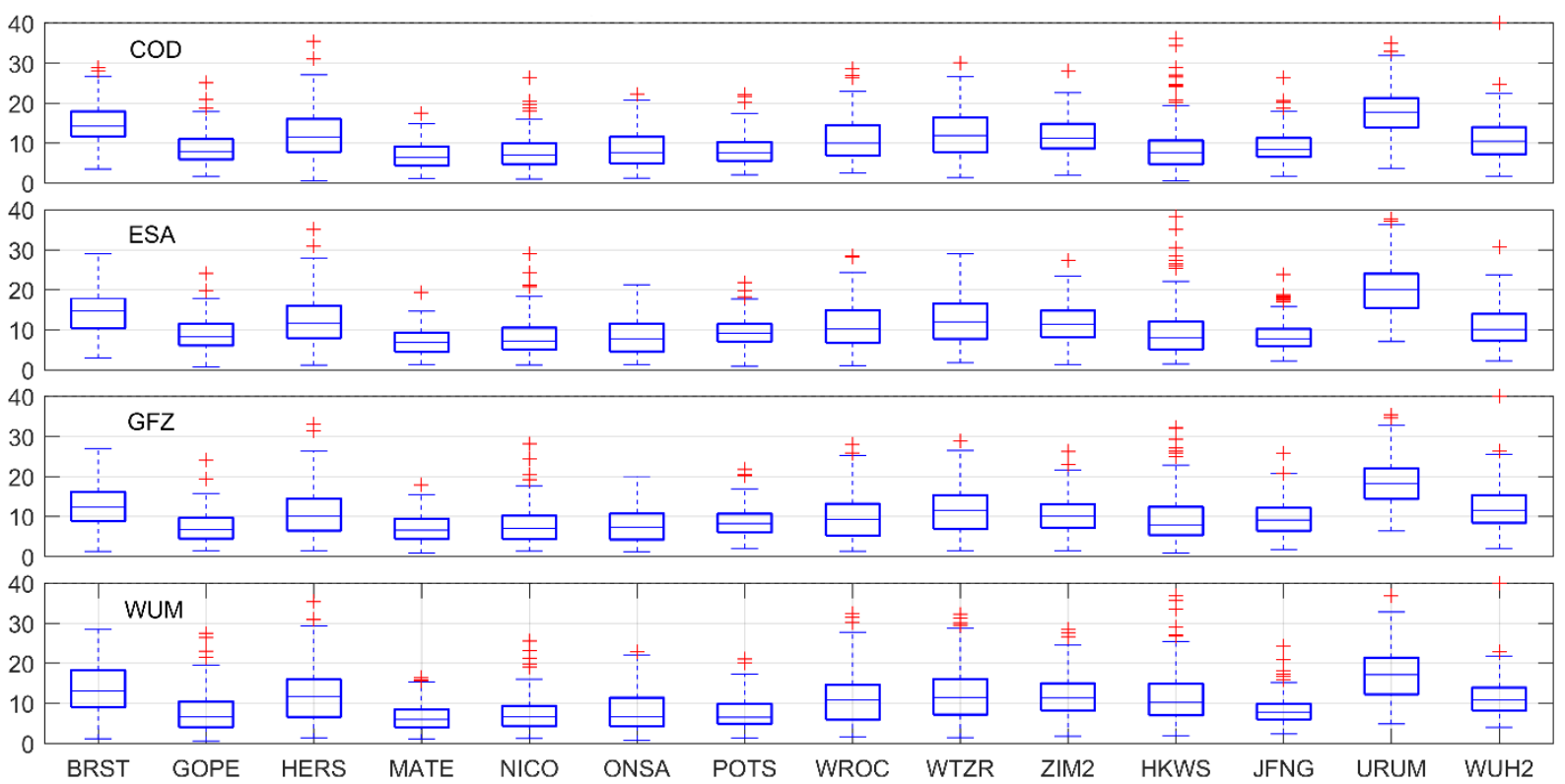

Fig. 2 Boxplot of 3D distance errors between coordinates from own PPP processing based on GRE constellation configuration using precise products from four selected ACs (top to bottom) and IGS weekly combined solution at all processed GNSS stations (left to right). All values are in $\mathrm{mm}$. 


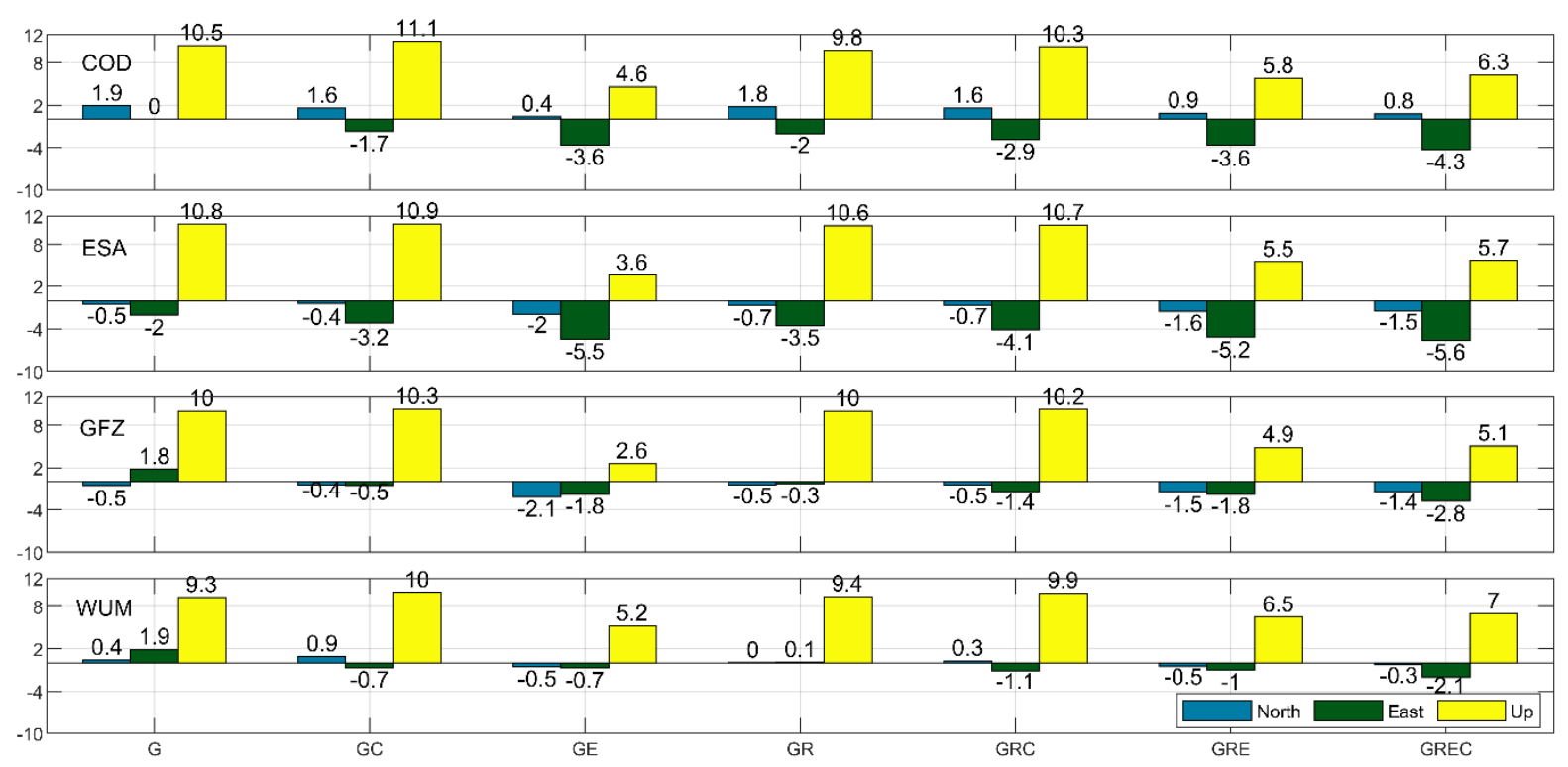

Fig. 3 Mean differences between daily coordinates from own PPP processing and IGS weekly combined solution in individual coordinate components (North, East, Up) computed over ten European stations. Values are given for specific precise products (top to bottom) and processed constellation configurations (left to right). All values are in $\mathrm{mm}$.

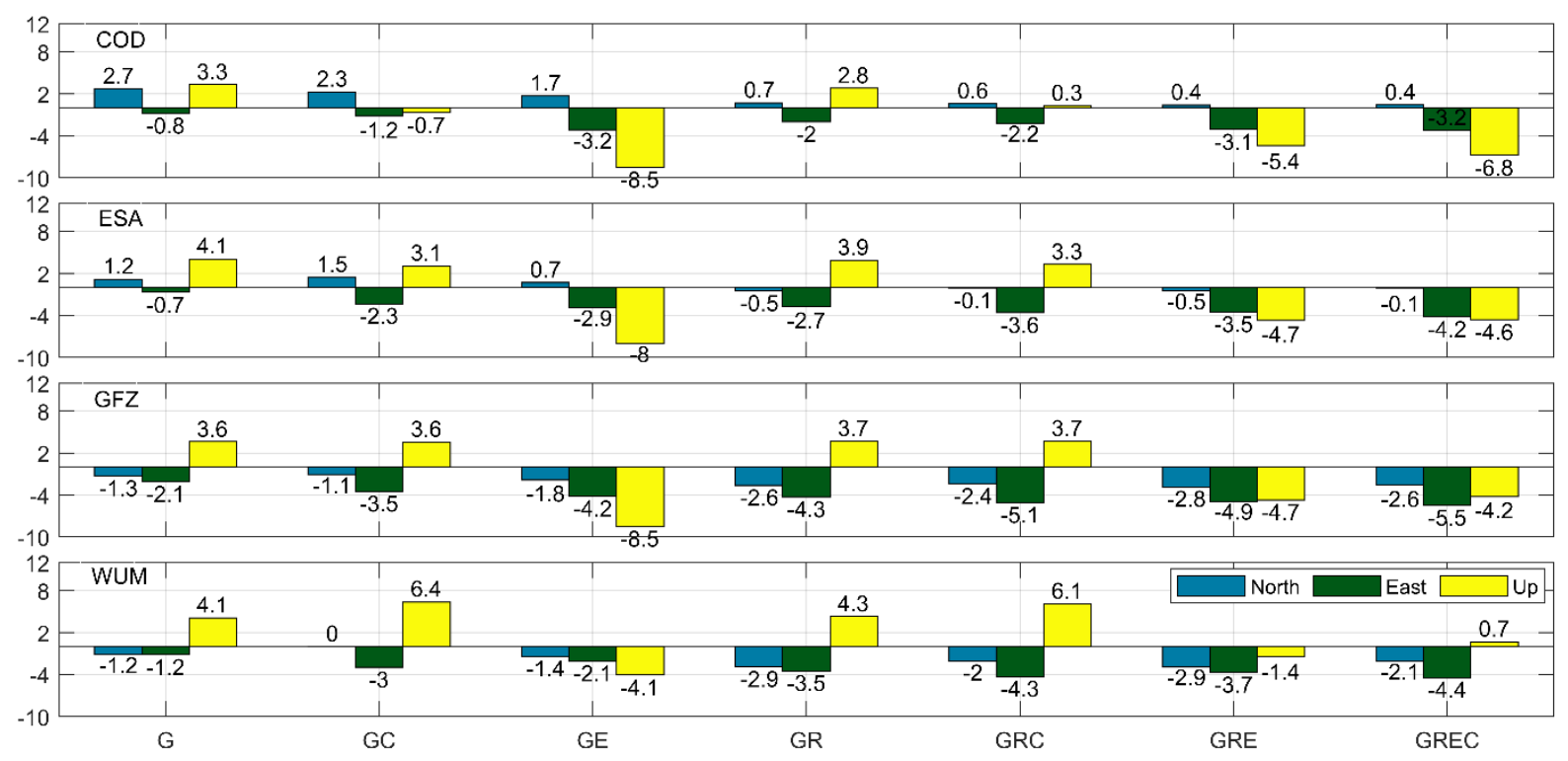

Fig. 4 Mean differences between daily coordinates from own PPP processing and IGS weekly combined solution in individual coordinate components (North, East, Up) computed over four Chinese stations. Values are given for specific precise products (top to bottom) and processed constellation configurations (left to right). All values are in $\mathrm{mm}$.

signals to the processing, a significant shift of about - 3 to -7 (-3 to -12$) \mathrm{mm}$ in the Up component was found for all precise products in results of all European (Chinese) stations. A similar shift of about $-2.5 \mathrm{~mm}$ was present also in the East component for GE solutions compared to GPS-only ones. This behavior has not been previously reported in any study based on GNSS data prior year 2020. It can be related to an increase in number of active Galileo satellites compared to previous years, continuous development of Galileo precise orbits and clocks products determination or potentially to a specific issue of the RTKLIB software.

Values of standard deviation (STD) and Root-Mean-Square error (RMS) shown in Figure 5 for European stations and in Figure 6 for Chinese stations were computed from 3D distance errors between own PPP processing and the IGS weekly combined solution. Since a high stability of coordinates from 

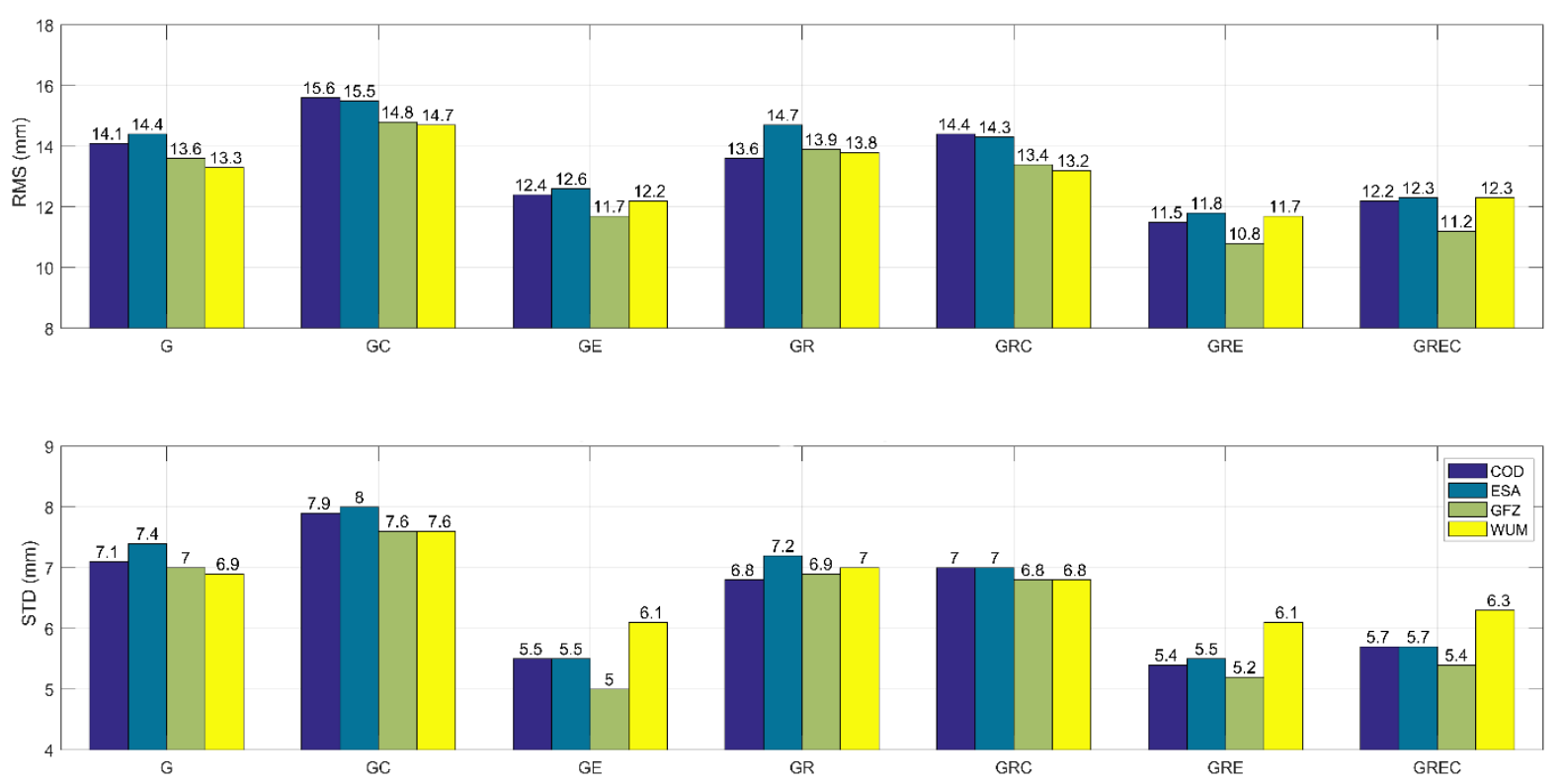

Fig. 5 RMS (top) and STD (bottom) values of 3D distance errors between coordinates from own PPP processing and IGS weekly combined solution computed over ten European stations.
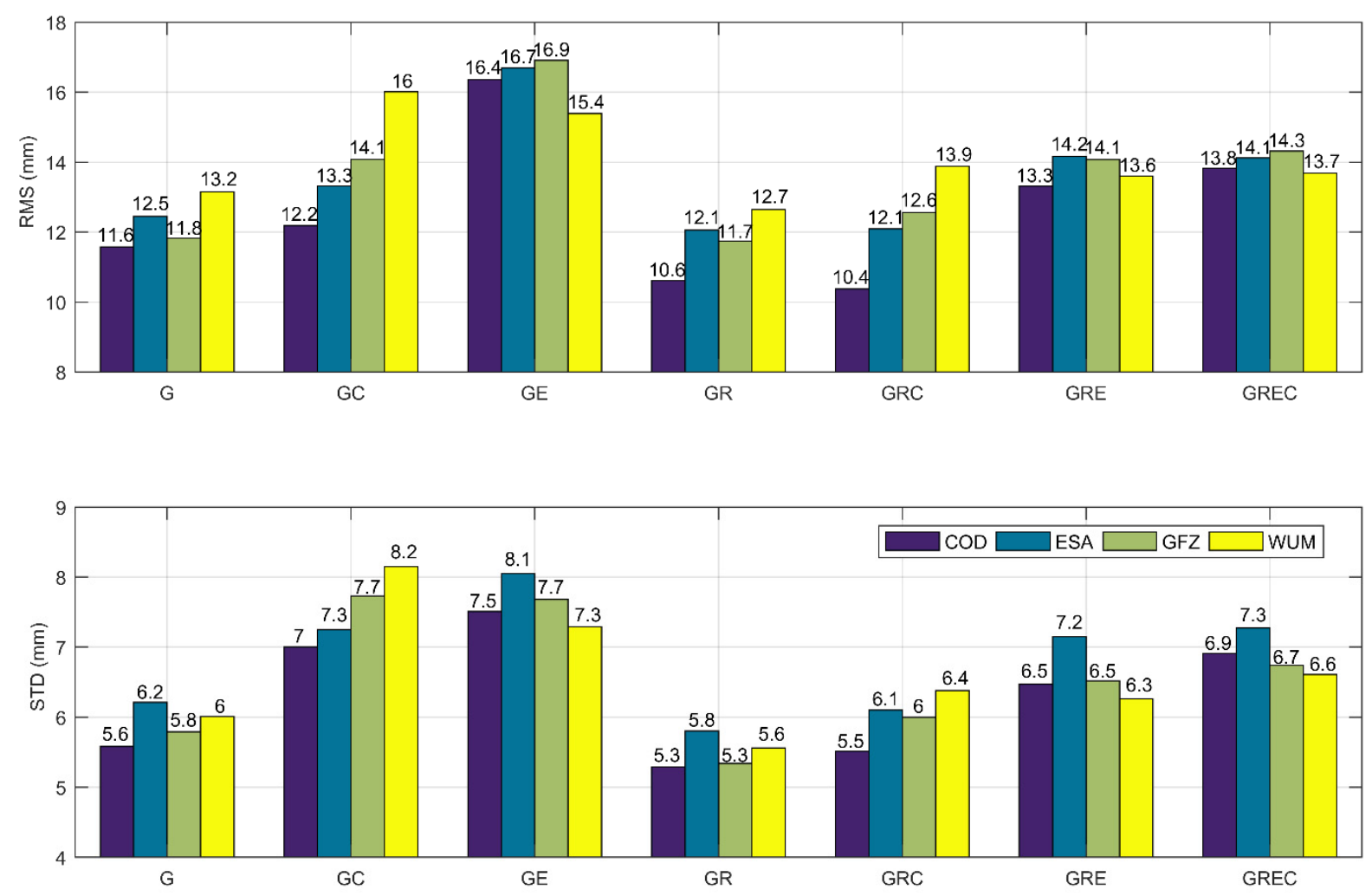

Fig. 6 RMS (top) and STD (bottom) values of 3D distance errors between coordinates from own PPP processing and IGS weekly combined solution computed over four Chinese stations.

IGS weekly combination can be expected, increase in STD is supposed to indicate a worse stability of RTKLIB positioning while using a particular constellation configuration or a particular precise product.
From the perspective of used constellation configuration, results of the STD values in Europe can be divided into three categories: 1) those provided by GE, GRE and GREC constellation configurations where COD, ESA and GFZ precise products oscillated 
around $5.5 \mathrm{~mm}$ and WUM product around $6.2 \mathrm{~mm}$; 2) those provided by G, GR and GRC constellation configurations where all the precise products oscillated around $7 \mathrm{~mm}$; 3) those provided by GC constellation configuration where STD values from individual precise products ranged between 7.6 and $8 \mathrm{~mm}$. As similar behavior was found also for RMS, it can be concluded that the closest positioning to the IGS final weekly product in Europe was reached with the GRE constellation configuration. It was followed by two other configurations which were also utilizing Galileo signals. The results indicate an ability of the Galileo system to improve precise positioning over Europe even under not fully operational constellation (22 Galileo satellites were active during the processed period). On the contrary, as the worst agreement with the used reference product was found for the GPS+BDS, inclusion of BDS system did not bring any visible positive impact. When evaluating individual multi-GNSS precise products, all of them provided very similar performance at European stations. Relative differences in STD and RMS values between individual precise products stayed mostly below $10 \%$. The only exception was WUM product in constellation configurations including Galileo satellites. In those cases, STD values were about $15-20 \%$ higher when compared to GFZ product which performed the best in this regard and about $5-10 \%$ higher when compared to COD and ESA products. If only one precise product was to be selected for Europe as providing the closest positioning to the IGS final weekly solution it would be the one from GFZ AC. However, as already mentioned, the differences between individual ACs were mostly minimal.

For stations located in China the results were different mainly in terms of Galileo system as its adding to constellation configuration led always to worse agreement with the reference product. The lowest STD and RMS values were achieved by GR constellation configuration with STD around $5.5 \mathrm{~mm}$. It was tightly followed by GPS-only and GRC solutions with STD around $6 \mathrm{~mm}$ and by GRE and GREC solutions with STD ranging between 6.3 and $7.3 \mathrm{~mm}$. STD values of GE and GC solutions were usually the highest reaching up to $8 \mathrm{~mm}$. In all constellation configurations, the lowest STD and RMS values for Chinese stations were mostly delivered by the COD product. Relative differences in STD and RMS values between individual precise products were similar to results of European stations, therefore typically below $10 \%$.

\subsection{STEP 2: COORDINATES REPEATABILITY}

Values of coordinate repeatability are presented in Figure 7 for European stations and in Figure 8 for Chinese stations. The reader is referred to Section 2.3 for an explanation of their computation. Lower values represent a better stability of positioning while occurring differences can be mainly attributed to
1) quality of used precise product; 2) impact of individual GNSS systems within used constellation configuration and 3) quality of observation data from processed GNSS stations.

In the horizontal direction, mean values computed over European (Chinese) GNSS stations ranged between 2.8 and $5.7 \mathrm{~mm}(2.4$ and $4.0 \mathrm{~mm})$ in the North component and between 4.8 and $8.6 \mathrm{~mm}$ (5.4 and $8.9 \mathrm{~mm}$ ) in the East component, depending on the constellation configuration and to a less extent also on the used precise product. Both in Europe and China, the best performance was obtained with GR solutions, typically followed with GPS-only and GRC.

In the vertical direction (Up component), larger differences between results for Europe and China were present. Mean values ranged between 6.2 and $7.6 \mathrm{~mm}$ in Europe and between 7.7 and $10.9 \mathrm{~mm}$ in China. Better stability of positioning in the Up component was therefore reached by European stations. Nevertheless, as only four Chinese stations were processed a significantly larger dataset would need to be used to reliably asses this phenomenon. Similarly, to the horizontal direction the best performance for the Up component was reached by GR. In Europe, GPS-only solutions were very close to them and were tightly followed by GRC and GRE. In China, GPS-only and GRC solutions were typically very close to the performance of GR. Usage of Galileo satellites in processing of Chinese stations led always to an increase of Up component repeatability up to $2.3 \mathrm{~mm}$.

As the lowest coordinate's repeatability in the 2D horizontal direction was almost always reached by the GR constellation configuration and the highest by GC and GE, inclusion of Galileo and BDS satellites did not provide any visible advantage for the realized daily static PPP positioning in post-processing mode in this regard. Nevertheless, the situation can be very much different when processing data from a shorter observation time and/or in real-time mode and/or in locations with a limited view over the sky. The described behavior was valid also for the European stations in the vertical direction, however the differences between GR and GE or GC were much smaller than those in horizontal direction. For Chinese stations, the repeatability of GC solutions in the vertical direction was close to the best performing GR, however GE remained the worst of all constellation configurations.

Differences in coordinates repeatability delivered by various precise products were dependent on particular constellation configuration. In those without Galileo they oscillated below or around $0.5 \mathrm{~mm}$ in North and East components, around $0.25 \mathrm{~mm}$ in Up component for European stations and reached up to $0.8 \mathrm{~mm}$ for Chinese stations in Up component. In GE, GRE and GREC constellation configurations, WUM product provided in Europe up to $1.1 \mathrm{~mm}(1.6 \mathrm{~mm})$ lower values in North (East) component compared to all other precise products. This situation was vice versa in Up component where WUM provided up to $0.5 \mathrm{~mm}$ 


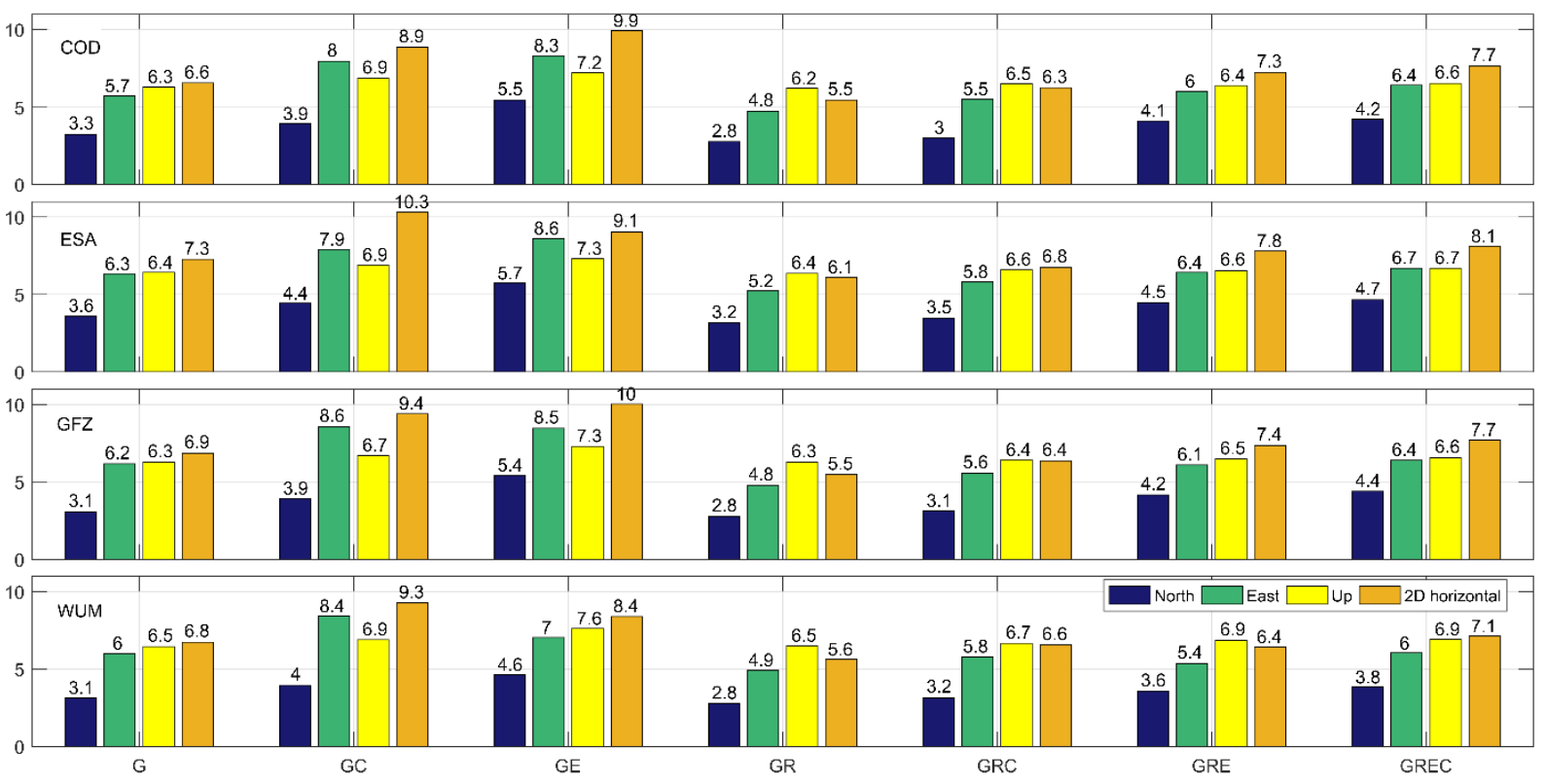

Fig. 7 Coordinates repeatability in N (North), E (East) and U (Up) components and in 2D horizontal direction using precise products from four ACs (top to bottom) and data from ten European GNSS stations. Results for individual constellation configurations are shown from the left to the right. All values are in $\mathrm{mm}$.
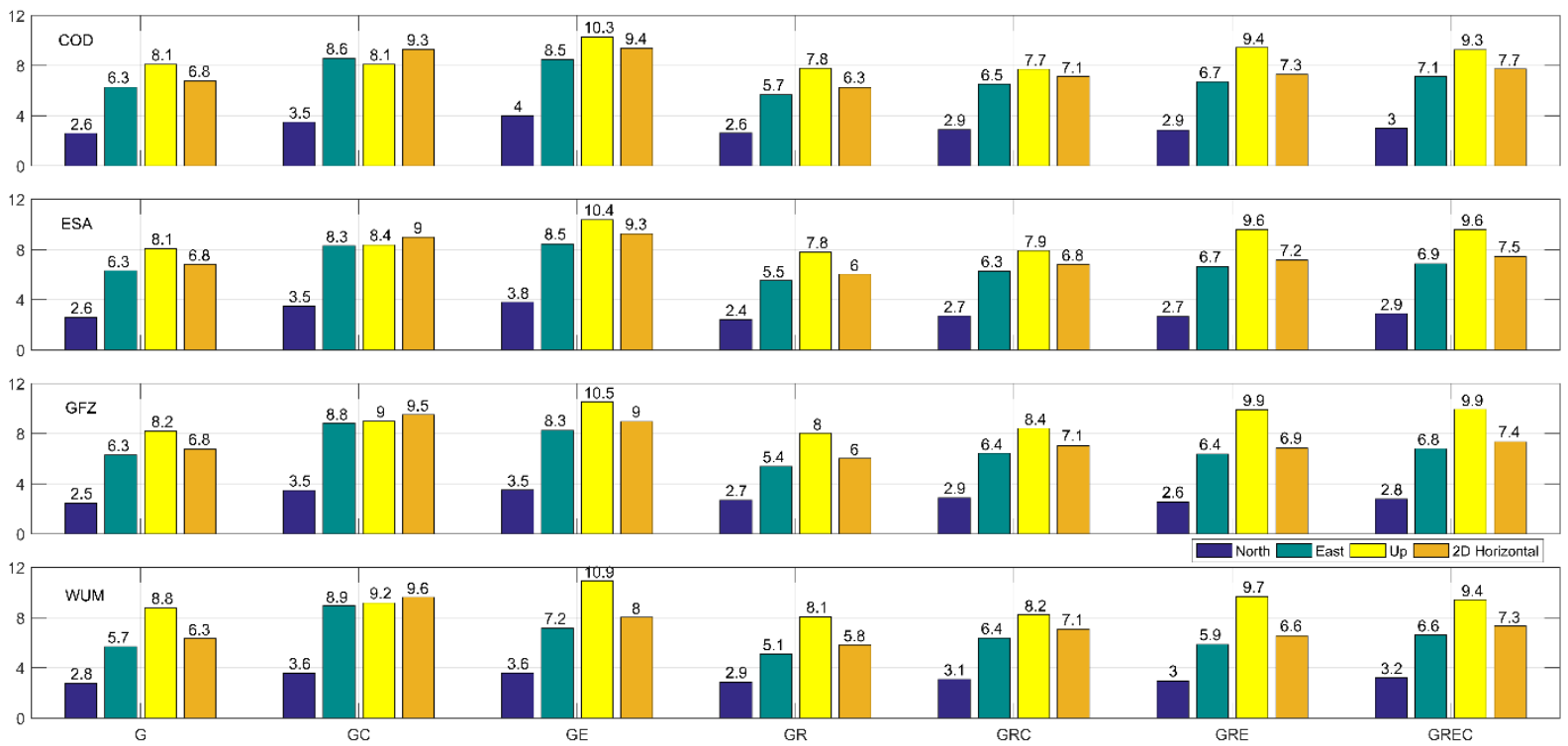

Fig. 8 Coordinates repeatability in N (North), E (East) and U (Up) components and in 2D horizontal direction using precise products from four ACs (top to bottom) and data from four Chinese GNSS stations. Results for individual constellation configurations are shown from the left to the right. All values are in $\mathrm{mm}$.

higher values than all other products. Similar behavior of WUM product in East and Up component was found also for Chinese stations in case of GE solutions, to a lesser extent in East component of GRE solutions and was not detectable in GREC solutions where all four products reached similar performance. Therefore, if Galileo signals are to be processed for a positioning application where coordinates repeatability plays an important role, choice of the precise product should be considered. Apart from the specific behavior of WUM product in constellation configurations including Galileo, the lowest coordinates repeatability values in Europe were typically provided by COD and GFZ product and the highest ones by ESA product (horizontal direction) and WUM product (vertical direction). In China, the results were more varying between individual constellation configurations and it was therefore not possible to select any precise product as the best or the worst performing in overall. 


\section{SUMMARY AND CONCLUSIONS}

PPP technique is nowadays being used in a broad list of applications for delivering accurate and precise positioning on all grades of receivers including the low-cost ones (see i.e. Aggrey et al., 2019). As already mentioned in the Introduction section, this can be achieved only if high-quality precise products with satellite orbits and clocks are available. Within the study, we have evaluated performance of multifrequency $24 \mathrm{~h}$ static post-processed PPP positioning in RTKLIB software while utilizing final multi-GNSS precise products from four analysis centers, seven different GNSS constellation configurations and observation data from ten European and four Chinese stations within five-month long period in 2020.

Firstly, coordinates obtained from own PPP processing were compared with those from the IGS final weekly solution which were taken as a reference. Based on the statistical evaluation of 3D distance errors, it was found out that in Europe constellation configurations including Galileo signals provided better positioning with respect to the reference product than others. The lowest RMS values at the level of $11 \mathrm{~mm}$ were reached by GRE, followed by GREC and GE with around $12 \mathrm{~mm}, \mathrm{G}$, GR, GRC with around $14 \mathrm{~mm}$ and $\mathrm{GC}$ with around $15 \mathrm{~mm}$. On the contrary, in China constellation configurations including Galileo satellites performed worse than others. It was mainly visible in GE which provided the highest RMS values at the level of $16 \mathrm{~mm}$ compared to the lowest $12 \mathrm{~mm}$ delivered by GR solutions. This situation indicates a more variable quality of Galileo precise products over China compared to Europe. It might be due to a less developed network of GNSS tracking stations used for determination of Galileo precise orbit and clocks over China. Although differences among individual precise products were mostly small, the best performance within the assessment was provided by precise product from GFZ AC for Europe and by the product from COD AC for China. They usually delivered the lowest values of standard deviation and RMS.

Secondly, coordinates repeatability over the whole processed period was computed in order to evaluate an impact of various constellation configurations and precise products on the positioning stability. In the horizontal direction, the lowest repeatability values were both in Europe and China reached by GR, therefore when processing a combination of signals from well-established GPS and GLONASS systems. GPS-only solutions reached typically the second lowest repeatability values in the horizontal direction. As inclusion of Galileo or BDS signals always led to worse results, the GPS system seemed to be still dominating the stability of $24 \mathrm{~h}$ PPP static solutions and new systems showing some level of deficiencies in this regard. The situation can be expected to change with reaching full operational capability by Galileo, further development of BDS system and improvements of their precise products quality. However, if the best possible coordinate repeatability in the horizontal direction needs to be achieved when applying a similar processing strategy as presented within this study, utilization of the GR constellation configuration can be recommended when processing data from the first half of 2020 or older. In the vertical direction, selection of the constellation configuration is less significant in Europe as G, GR, GRC, GRE and GREC provided very similar repeatability differing only at the level of $0.3 \mathrm{~mm}$. In China, a similar behavior was found for $\mathrm{G}$, GR and GRC, however any inclusion of Galileo system led to an increase in repeatability of at least $1.2 \mathrm{~mm}$. From the perspective of precise products, the repeatability results were dependent on the selected constellation configuration where mainly a specific behavior of WUM product for Galileo system was observed. Still, in Europe precise products from COD and GFZ provided relatively better overall performance than those from ESA and WUM. In China, the overall performance of individual precise products was more varying and it was not possible to choose one which would be systematically better.

\section{REFERENCES}

Aggrey, J., Bisnath, S., Naciri, N., Shinghal, G. and Yang, S.: 2019, Multi-GNSS precise point positioning with next-generation smartphone measurements. J. Spat. Sci., 65, 79-98. DOI: $10.1080 / 14498596.2019 .1664944$

Bahadur, B. and Nohutcu, M.: 2019, Comparative analysis of MGEX products for post-processing multi-GNSS PPP. Measurement, 145, 361-369. DOI: 10.1016/j.measurement.2019.05.094

Cai, Ch., Gao, Y., Pan, L. and Zhu, J.: 2015, Precise point positioning with quad-constellations: GPS, BeiDou, GLONASS and Galileo. Adv. Space Res., 56, 133143. DOI: 10.1016/j.asr.2015.04.001

Douša, J., Václavovic, P., Zhao, L. and Kačmařík, M.: 2018, New adaptable all-in-one strategy for estimating advanced tropospheric parameters and using real-time orbits and clocks. Remote Sens., 10, 232. DOI: $10.3390 / \mathrm{rs} 10020232$

Gandolfi, S., Tavasci, L. and Poluzzi, L.: 2017, Study on GPS-PPP precision for short observation sessions. GPS Solut., 21, 887-896. DOI: $10.1007 / \mathrm{s} 10291-016-0575-4$

Geng, J., Meng, X., Teferle, N. and Dodson, A. H.: 2010, Performance of Precise Point Positioning with ambiguity resolution for 1- to 4-hour observation periods. Surv. Rev., 42, 316, 155-165. DOI: $10.1179 / 003962610 X 12572516251682$

Guo, J., Xu, X., Zhao, Q. and Liu, J.: 2016, Precise orbit determination for quad-constellation satellites at Wuhan University: strategy, result validation, and comparison. J. Geod., 90, 143-159. DOI: $10.1007 / \mathrm{s} 00190-015-0862-9$

Guo, F., Li, X., Zhang, X. and Wang, J.: 2017a, The contribution of Multi-GNSS Experiment (MGEX) to precise point positioning. Adv. Space Res., 59, 11, 2714-2725. DOI: 10.1016/j.asr.2016.05.018

Guo, F., Li, X., Zhang, X. and Wang, J.: 2017b, Assessment of precise orbit and clock products for Galileo, 
BeiDou, and QZSS from IGS Multi-GNSS Experiment (MGEX). GPS Solut., 21, 279-290. DOI: $10.1007 / \mathrm{s} 10291-016-0523-3$

International GNSS Service: Final Combined Station Positions/Velocities (no covariance matrix) Product, Greenbelt, MD, USA: NASA Crustal Dynamics Data Information System (CDDIS), Accessed April 1, 2021 at DOI: $10.5067 /$ GNSS/gnss_igsssc_001

Johnston, G., Riddell, A. and Hausler, G.: 2017, The International GNSS Service. In Springer Handbook of. Global Navigation Satellite Sys-tems, 1st ed., Teunissen, P., Montenbruck, O., Eds., Cham, Switzerland, 967-982. DOI: $10.1007 / 978-3-319-42928-1$

Kazmierski, K., Sośnica, K. and Hadas, T.: 2018, Quality assessment of multi-GNSS orbits and clocks for realtime precise point positioning. GPS Solut., 22, 11. DOI: $10.1007 / \mathrm{s} 10291-017-0678-6$

Kiliszek, D., Szołucha, M. and Kroszczynski, K.: 2018, Accuracy of Precise Point Positioning (PPP) with the use of different International GNSS Service (IGS) products and stochastic modelling. Geodesy Cartogr., 67, 2, 207-238. DOI: 10.24425/gac.2018.125472

Li, W. and Kačmařík, M.: 2021, Assessment of the MultiGNSS PPP performance using precise products from the Wuhan analysis centre. Proc. GIS Ostrava 2021 Advances in Localization and Navigation Symposium. Ostrava, the Czech Republic, 17-19 March 2021. DOI: $10.31490 / 9788024845050-9$

Li, X., Ge, M., Dai, X., Ren, X., Fritsche, M., Wickert, J. and Schuh, H.: 2015, Accuracy and reliability of multi-GNSS real-time precise positioning: GPS, GLONASS, BeiDou, and Galileo. J. Geod., 89, 607635. DOI: 10.1007/s00190-015-0802-8

Li, X., Pan, L., Zhang, X., Liu, J. and Li, X.: 2017, Performance evaluation of single-frequency Precise Point Positioning with GPS, GLONASS, BeiDou and Galileo. J. Navig., 70, 3, 465-482.

DOI: $10.1017 / \mathrm{S} 0373463316000771$

Li, X., Zhu, Y., Zheng, K., Yuan, Y., Liu, G. and Xiong, Y.: 2020, Precise orbit and clock products of Galileo, BDS and QZSS from MGEX since 2018: Comparison and PPP validation. Remote Sens., 12, 9.

DOI: $10.3390 / R S 12091415$

Mohammed, J., Moore, T. and Hill, Ch.: 2018, An assessment of the precise products on static Precise Point Positioning using Multi-Constellation GNSS. Proc. 2018 IEEE/ION Position, Location and Navigation Symposium, PLANS 2018. Monterey, United States, 23-26 April 2018.

Montenbruck, O., Steigenberger, P., Khachikyan, R., Weber, G., Langley, R.B., Mervart, L. and Hugentobler, U.: 2014, IGS-MGEX: Preparing the Ground for Multi-Constellation GNSS Science. Inside GNSS, 9, 1, 42-49.

Montenbruck, O., Steigenberger, P., Prange, L., Deng, Z., Zhao, Q., Perosanz, F., Romero, I., Noll, C., Stürze, A., Weber, G., Schmid, R., MacLeod, K. and Schaer, S.: 2017, The Multi-GNSS experiment (MGEX) of the International GNSS Service (IGS) - Achievements, prospects and challenges. Adv. Space Res., 59, 7, 1671-1697. DOI: 10.1016/j.asr.2017.01.011

Niell, A.E.: 1996, Global mapping for the atmospheric delay at radio wavelenghts. J. Geophys. Res., 101, B2, 3227-3246. DOI: 10.1029/95JB03048
Odolinski, R. and Teunissen, P.J.G.: 2017, Low-cost, 4-system, precise GNSS positioning: A GPS, Galileo, BDS and QZSS ionosphere-weighted RTK analysis. Meas. Sci. Technol., 28, 12, 125801. DOI: $10.1088 / 1361-6501 / \mathrm{aa} 92 \mathrm{eb}$

Pan, L., Zhang, X., Li, X., Lu, C., Liu, J. and Wang, Q.: 2019, Satellite availability and point positioning accuracy evaluation on a global scale for integration of GPS, GLONASS, BeiDou and Galileo. Adv. Space Res., 63, 2696-2710. DOI: 10.1016/j.asr.2017.07.029

Prange, L., Arnold, D., Dach, R., Kalarus, M., Schaer, S., Stebler, P., Villigerturo, A. and Jäggi, A.: 2020, CODE product series for the IGS MGEX project. Astronomical Institute, University of Bern. DOI: 10.7892 /boris. 75882.3

Saastamoinen, J.: 1973, Contributions to the theory of atmospheric refraction. Bull. Geodesique, 107, 1, 1334. DOI: $10.1007 / \mathrm{BF} 02522083$

Steigenberger, P. and Montebruck, O.: 2020, Consistency of MGEX Orbit and Clock Products. J. Eng., 6, 8, 898903. DOI: $10.1016 /$ j.eng.2019.12.005

Takasu, T.: 2009, RTKLIB: Open Source Program Package for RTK-GPS. Proc. FOSS4G 2009, Tokyo, Japan, November 2, 2009.

Tegedor, J., Øvstedal, O. and Vigen, E.: 2014, Precise orbit determination and point positioning using GPS, Glonass, Galileo and BeiDou. J. Geod. Sci., 4, 65-73. DOI: $10.2478 /$ jogs-2014-0008

Wang, Z., Li, Z., Wang, L., Wang, X. and Yuan, H.: 2018, Assessment of multiple GNSS real-time SSR products from different analysis centers. ISPRS Int. J. Geoinf., 7, 3, 85. DOI: 10.3390/ijgi7030085

Zhao, X., Ge, Y., Ke, F., Liu, C. and Li., F.: 2020, Investigation of real-time kinematic multi-GNSS precise point positioning with the CNES products. Measurement, 166, 108231.

DOI: 10.1016/j.measurement.2020.108231

Zhou, F., Cao, X., Ge, Y. and Li, W.: 2020, Assessment of the positioning performance and tropospheric delay retrieval with precise point positioning using products from different analysis centers. GPS Solut., 24, 12. DOI: $10.1007 / \mathrm{s} 10291-019-0925-0$

Zumberge, J.F., Heflin, M.B., Jefferson, D.C., Watkins, M.M. and Webb, F.H.: 1997, Precise Point Positioning for the efficient and robust analysis of GPS data from large networks. J. Geophys. Res., 102, B3, 5005. DOI: $10.1029 / 96 J B 03860$ 